\author{
深 \\ 田 \\ 悟*1

\section{A Three-Dimensional Model of Magnetic Reluctance of Rectangular Iron Core} \\ Satoru FUKATA*2 \\ ${ }^{* 2}$ Faculty of Design, Kyushu University, \\ 4-9-1 Shiobaru, Mimami-ku, Fukuoka-shi, Fukuoka, 815-8540 Japan

\begin{abstract}
A three-dimensional distribution of magnetic filed is considered to obtain an analytical model of the magnetic reluctance of rectangular iron-cores whose ends face to the working airgaps in a magnetic system. The reluctance model is compared with a simple model based on the two-dimensional distribution to check the validity of this simple model for the effects of the length of iron core. First, the magnetic field is solved under an assumption that the magnetic intensity is uniform and perpendicular to the end surfaces. To obtain an analytical solution, however, a natural condition is neglected that the magnetic intensity is uniform on the side surfaces parallel to the longitudinal direction. Also, the concept of generalized functions is applied to discuss the convergence of an infinite cosine-function series; hence the result obtained is an approximation. Next, the magnetic reluctance is obtained from the magnetomotive force along the iron-core surface divided by the magnetic flux. The reluctance is expressed with two parts: a term corresponding to two-dimensional model and a term with a function of the iron-core length. Approximate equations are presented to avoid poor convergence of double infinite series, and numerical examples are given to show the results.
\end{abstract}

Key Words : Actuator, Magnetic Actuator, Modeling, Magnetic Reluctance, Rectangular Iron Core, Frequency Characteristics

\section{1.まえがき}

電磁石アクチュエータでは, 積層鉄心の利用が困難 な場合やいくつかの目的のためにソリッド鉄心が用い られることがある. あまり関心を持たれていないため か, この場合のモデリングや動特性のデータについて は報告が少ない. 矩形鉄心の電磁石系のモデルとして, 鉄心内の磁界を軸方向に一様な二次元分布であると仮 定して求めた磁気抵抗モデル(1)を基にして, 解析的な モデル (二次元モデル) ${ }^{(2)}$ が提案されている. このモデ ルはもともと直線磁路の矩形鉄心に対するものである が, 表現式が簡単で使い易いことから，I 字形やU字 形の鉄心に対しても著者は利用しており，実測データ との比較を行ってきた.

二次元モデルと実測值との一致度は低周波数域では 実用上支障はないと思われるが，数十 $\mathrm{Hz}$ 以上ではよ くない(2),(3).これにはいくつかの理由が考えられるが， 電磁石コイルが鉄心に一様に巻かれているというモデ

* 原稿受付 2006 年 3 月 16 日.

*1 正員, 九州大学芸術工学研究院 (E 815-8540 福岡市南区塩 原 4-9-1).

E-mail : fukata@design.kyushu-u.ac.jp
リングの前提条件や，鉄心の空隙部付近での磁界の三 次元分布が影響しているかもしれない，本論文の主な 目的はこのことを明らかにして, 二次元モデルの有用 性を検討することである.

この種の解析には一般的には数值解析が有用であろ う. 一方, 著者は先に, 空隙部に挟まれた, 鉄心幅が 十分に広い一次元鉄心に対して，磁界の二次元分布を 表す式を解析的に求めた ${ }^{(4)}$.ここではこの結果を拡張 して利用するために，同様に解析的な手法を採る．ま た, 解析モデルは解析的な二次元モデルとの比較に直 接的でわかりやすい.

ここでは，一つの解析解を得るために，鉄心の側面 では磁界の強さは周囲方向について一様であるという 自然な条件を無視する. また, 通常の意味では収束し ない, 三角関数の無限級数の和を一般化関数 (超関数) の意味でデル夕関数に収束するとして取り扱う.その ような意味で, ここで求める磁界分布は一つの近似で ある.

この近似分布から，鉄心の長さを考虑した磁気抵抗 モデル(三次元モデル)を求める.このモデルを用いて, 鉄心長さの影響を調べ, 空隙部の影響を無視した, 二 次元モデルの妥当な範囲を推定する資料にする. 


$$
\int_{-b / 2}^{b / 2} \int_{-a / 2}^{a / 2} H_{z}(x, y, z) d x d y=a b H_{0}
$$

一方，長さ方向の磁界の強さはその方向に垂直な断 面の周囲では一様であるとみなすのが自然である.こ のとき，次の条件が課される.

$$
H_{z}\left( \pm \frac{a}{2}, y, z\right)=H_{z}\left(x, \pm \frac{b}{2}, z\right)
$$

条件の式(6)一(10)をすべて満たす解析解が存在す るかどうかは不明である，以下では，式(10)の条件を 除外して解析解を見出すことを試みる.

3.2 近似解の関係式 上の関係式を変数の初期值 をゼロとしてラプラス変換する. そして, 簡単のため に, $H_{x}(x, y, z)$ のラプラス変換 $H_{x}(x, y, z, s)$ の代わり に, $H_{0}$ のラプラス変換 $H_{0}(s)$ で正規化した変数

$$
h_{x}=h_{x}(x, y, z, s)=\frac{H_{x}(x, y, z, s)}{H_{0}(s)}
$$

を用いる. $h_{y}$ と $h_{z}$ についても同様である. このとき， 式(1)一(9)は以下のように置き換えられる.

\section{磁界の関係}

$$
\begin{aligned}
& \nabla^{2} h_{x}=\alpha^{2} h_{x}, \quad \nabla^{2} h_{y}=\alpha^{2} h_{y} \\
& \nabla^{2} h_{z}=\alpha^{2} h_{z} \\
& \frac{\partial h_{x}}{\partial x}+\frac{\partial h_{y}}{\partial y}+\frac{\partial h_{z}}{\partial z}=0 \\
& \text { ここで, } s \text { をラプラス変数として, } \\
& \alpha^{2}=\mu \sigma s
\end{aligned}
$$

境界条件と制約条件

$$
\begin{aligned}
& h_{x}\left( \pm \frac{a}{2}, y, z, s\right)=0, \quad h_{x}\left(x, \pm \frac{b}{2}, z, s\right)=0 \\
& h_{y}\left(x, \pm \frac{b}{2}, z, s\right)=0, \quad h_{y}\left( \pm \frac{a}{2}, y, z, s\right)=0 \\
& h_{z}\left(x, y, \pm \frac{l}{2}, s\right)=1 \\
& \int_{-b / 2}^{b / 2} \int_{-a / 2}^{a / 2} h_{z}(x, y, z, s) d x d y=a b
\end{aligned}
$$

3.3 磁界の表現式断面方向の磁界が類似な形 をしていると予想されることを考慮して， $h_{x}$ と $h_{y}$ か ら取り上げる. 式(12)を変数分離法で解くと, いくつ かの組み合わせが考えられるが，関数の予想形と境界 条件式(16) と (17) を考慮すると, 次の形が予想される.

$$
\begin{aligned}
& h_{x}=\sum_{n=1}^{\infty} \sum_{m=0}^{\infty} a_{n m} \sin \left(p_{a n} x\right) \cos \left(q_{b m} y\right) \frac{\sinh \left(\xi_{n m} z\right)}{\cosh \left(\xi_{n m} l / 2\right)} \\
& h_{y}=\sum_{n=1}^{\infty} \sum_{m=0}^{\infty} b_{n m} \sin \left(p_{b n} y\right) \cos \left(q_{a m} x\right) \frac{\sinh \left(\eta_{n m} z\right)}{\cosh \left(\eta_{n m} l / 2\right)}
\end{aligned}
$$

$$
\begin{aligned}
& \xi_{n m}{ }^{2}=\alpha^{2}+p_{a n}{ }^{2}+q_{b m}{ }^{2}, \\
& \eta_{n m}{ }^{2}=\alpha^{2}+p_{b n}{ }^{2}+q_{a m}{ }^{2} \\
& p_{a n}=\frac{2 \pi}{a} n, \quad p_{b n}=\frac{2 \pi}{b} n \\
& q_{a m}=\frac{\pi}{a}(2 m+1), \quad q_{b m}=\frac{\pi}{b}(2 m+1)
\end{aligned}
$$

$h_{z}$ については，まず，その形を連続の式(14)から求 める方が簡単であろう.このとき, 任意定数を勘案し て, 境界条件式(18)を考慮し, 文献(4)の表示式を参考 にして次のように表してみる.

$$
\begin{aligned}
& h_{z}=1 \\
& +\sum_{n, m}^{\infty} c_{n m} \cos \left(p_{a n} x\right) \cos \left(q_{b m} y\right)\left[1-\frac{\cosh \left(\xi_{n m} z\right)}{\cosh \left(\xi_{n m} l / 2\right)}\right] \\
& +\sum_{n, m}^{\infty} d_{n m} \cos \left(p_{b n} y\right) \cos \left(q_{a m} x\right)\left[1-\frac{\cosh \left(\eta_{n m} z\right)}{\cosh \left(\eta_{n m} l / 2\right)}\right]
\end{aligned}
$$

ここで, 係数間に次の関係がある.

$$
a_{n m}=\frac{\xi_{n m}}{p_{a n}} c_{n m}, \quad b_{n m}=\frac{\eta_{n m}}{p_{b n}} d_{n m}
$$

次に, 式(25)を式(13)に代入して整理すると次式の ように書ける.

$$
\nabla^{2} h_{z}=\alpha^{2} h_{z}-\alpha^{2} f(x, y)
$$

ここで,

$$
\begin{array}{r}
f(x, y)=1+\frac{1}{\alpha^{2}} \sum_{n, m}^{\infty}\left[c_{n m} \xi_{n m}^{2} \cos \left(p_{a n} x\right) \cos \left(q_{b m} y\right)\right. \\
\left.+d_{n m} \eta_{n m}{ }^{2} \cos \left(p_{b n} y\right) \cos \left(q_{a m} x\right)\right]
\end{array}
$$

このとき, $f(x, y)=0$ を満たすように係数を定めるこ とが可能であろうか. これは上の余弦関数の二重無限 級数和で定数 1 を近似できるかどうかの問題であり， このままでは解くことが困難であるとみられる.

ところで, 式(25)の表現では, 境界面 $x= \pm a / 2$ ま たは $y= \pm b / 2$ で, 磁界の強さが $y$ または $x$ の関数で, 一般に式(10) が満たされない。[角部での条件 $\left(x= \pm a / 2\right.$ かつ $y= \pm b / 2$ で $\left.h_{z}=1\right)$ が保証されない という点については，無限級数展開が関わるので簡単 には判定しがたい. ]したがって，式(20)，(21)，(25) はもとの問題の近似解表現であるといえる.

3.4 係数の操作 上の磁界の表現が一次元鉄心 モデルを含むように，例えば, $a \rightarrow \infty$ のき，式(25) で第一項が消え，式(20)が消失するようにしたい，そ のために，係数間の関係式(26)を考慮して，係数を次 のように操作する.

$$
c_{n m}=\frac{b}{a+b} \bar{c}_{n m}, \quad d_{n m}=\frac{a}{a+b} \bar{d}_{n m}
$$

このとき，式(28)は次のように表される. 


$$
\begin{aligned}
& f(x, y)=\frac{b}{a+b}\left[1+\sum_{n, m}^{\infty} \frac{\xi_{n m}^{2}}{\alpha^{2}} \bar{c}_{n m} \cos \left(p_{a n} x\right) \cos \left(q_{b m} y\right)\right] \\
& +\frac{a}{a+b}\left[1+\sum_{n, m}^{\infty} \frac{\eta_{n m}^{2}}{\alpha^{2}} \vec{d}_{n m} \cos \left(p_{b n} y\right) \cos \left(q_{a m} x\right)\right]
\end{aligned}
$$

\section{4. 一般化関数による係数の決定}

4.1 デルタ関数のフーリエ級数展開式 デルタ関 数 (インパルス関数) $\delta(t)$ ( $t$ は一般的な変数) は取り扱 いにくい関数であるが，関数を一般化した取り扱いで は次のよううにフーリエ級数展開される(7), (8).

$$
\begin{aligned}
\delta_{T}(t) & =\sum_{n=-\infty}^{n=\infty} \delta(t-n T) \\
& =\frac{1}{T}+\frac{2}{T} \sum_{n=1}^{n=\infty} \cos \left(\frac{2 \pi n}{T} t\right)
\end{aligned}
$$

ここで, $T$ は周期である. 上式第二項の余弦級数は通 常の定檥では収束しないが，一般化関数の取り扱いで は収束するとみなされる。

上の関係を $1 / 4$ 周期分移行させた関数 $\delta_{T}(t-T / 4)$ は次のように表される.

$$
\delta_{T}\left(t-\frac{T}{4}\right)=\frac{1}{T}+\frac{2}{T} \sum_{n=1}^{n=\infty}(-1)^{n} \cos \left(\frac{2 \pi n}{T} t\right)
$$

ここで, $T=a, t=x$ とし， $|x| \leq a / 2$ に限定すると， 次のように書かれる.

$$
\begin{aligned}
\delta_{a}(x) & =\delta\left(x+\frac{a}{2}\right)+\delta\left(x-\frac{a}{2}\right) \\
& =\frac{1}{a}+\frac{2}{a} \sum_{n=1}^{n=\infty}(-1)^{n} \cos \left(\frac{2 \pi n}{a} x\right)
\end{aligned}
$$

4.2 係数の決定 フーリエ級数展開から次の関 係が得られる ${ }^{(7)}$.

$$
1=\frac{4}{\pi} \sum_{m=0}^{\infty} \frac{(-1)^{m}}{2 m+1} \cos \left[\frac{\pi}{b}(2 m+1) y\right],|y|<\frac{b}{2}
$$

式(33)の第二項にこの関係を乗じると次の関係を得る.

$$
a \delta_{a}(x)=1+\frac{8}{\pi} \sum_{n, m} \frac{(-1)^{n+m}}{2 m+1} \cos \left(p_{a n} x\right) \cos \left(q_{b m} y\right)
$$

同様にして

$$
\begin{gathered}
b \delta_{b}(y)=1+\frac{8}{\pi} \sum_{n, m} \frac{(-1)^{n+m}}{2 m+1} \cos \left(p_{b n} y\right) \cos \left(q_{a m} x\right) \\
|x|<\frac{a}{2}, \quad|y| \leq \frac{b}{2}
\end{gathered}
$$

式(30)を式(35)，(36) と比較して,

$$
\begin{aligned}
& \bar{c}_{n m}=\frac{8}{\pi} \frac{(-1)^{n+m}}{2 m+1} \frac{\alpha^{2}}{\xi_{n m}{ }^{2}}, \\
& \bar{d}_{n m}=\frac{8}{\pi} \frac{(-1)^{n+m}}{2 m+1} \frac{\alpha^{2}}{\eta_{n m}{ }^{2}}
\end{aligned}
$$

のように選ぶと, 式(30)は次のように書かれる.

$$
\begin{aligned}
f(x, y)=\frac{a b}{a+b} & {\left[\delta\left(x+\frac{a}{2}\right)+\delta\left(x-\frac{a}{2}\right)\right.} \\
+ & \left.\delta\left(y+\frac{b}{2}\right)+\delta\left(y-\frac{b}{2}\right)\right]
\end{aligned}
$$

したがって, 係数を上のように選ぶと, 鉄心の長さ方 向の磁界の関係式は境界面以外で成立寸るといえる. 境界面の磁界は, 上の結果で $x \rightarrow \pm a / 2, y \rightarrow$ $\pm b / 2$ として定めることにする.

以上のことから, 式(37)から得られる式(29)の倸数 と, それらから得られる式(26)の倸数を用いて, 磁界 分布は式(20)，(21)，(25)で表される.

\section{5. 磁续抵抗モデル}

5.1 起磁力 鉄心表面の長さ方向の起磁力を次式 で定める.

$$
\begin{aligned}
& f_{m 1}(y)=\int_{-l / 2}^{l / 2} h_{z}\left( \pm \frac{a}{2}, y, z, s\right) d z \\
& f_{m 2}(x)=\int_{-l / 2}^{l / 2} h_{z}\left(x, \pm \frac{b}{2}, z, s\right) d z
\end{aligned}
$$

そして，これらが一様でないので平均的な起磁力を次 式から求める.

$$
f_{m}=\frac{1}{a+b}\left[\int_{-b / 2}^{b / 2} f_{m 1}(y) d y+\int_{-a / 2}^{a / 2} f_{m 2}(x) d x\right]
$$

このとき，次のように表される.

$$
\begin{aligned}
r_{m}(s) & =\frac{f_{m}}{l} \\
= & 1+\left(\frac{b}{a+b}\right)^{2} \bar{f}_{m 1}+\left(\frac{a}{a+b}\right)^{2} \bar{f}_{m 2} \\
こ こ て ゙, & \\
\bar{f}_{m 1}= & S_{a b}\left(\xi_{n m}\right)-S_{l}\left(\xi_{n m}\right) \\
\bar{f}_{m 2} & =S_{a b}\left(\eta_{n m}\right)-S_{l}\left(\eta_{n m}\right) \\
S_{a b}\left(\xi_{n m}\right) & =\frac{16}{\pi^{2}} \sum_{n, m}^{\infty} \frac{1}{(2 m+1)^{2}} \frac{\alpha^{2}}{\xi_{n m}^{2}} \\
S_{l}\left(\xi_{n m}\right) & =\frac{16}{\pi^{2}} \sum_{n, m}^{\infty} \frac{1}{(2 m+1)^{2}} \frac{\alpha^{2}}{\xi_{n m}{ }^{2}} \frac{\tanh \left(\xi_{n m} l / 2\right)}{\xi_{n m} l / 2}
\end{aligned}
$$

$S_{a b}\left(\eta_{n m}\right)$ と $S_{l}\left(\eta_{n m}\right)$ についても同様である.

式(42)と（43）のそれぞれ第一項は鉄心の長さから独 立な項で, 第二項は鉄心の長さの影響を示寸項である. $\alpha \rightarrow 0$ ではいずれの項もぜロになる.

5.2 磁気抵抗磁気抵抗を次のように表す。

$$
R_{m}(s)=\frac{f_{m} H_{0}(s)}{\mu a b H_{0}(s)}=R_{m 0} r_{m}(s)
$$

ここで, $R_{m 0}$ は次式の静的な磁気抵抗で, $r_{m}(s)$ はそ れに相対的な磁気抵抗である.

$$
R_{m 0}=\frac{l}{\mu a b}
$$


式(44) と(45)の計算では, 高周波数域で $\alpha^{2}$ の項が 大きくなって, $n$ についての収束性が非常に悪い. 式 （44）についてはこれを改善することができる．まず， 同じ関数について，次の二つの異なったフーリエ級数 展開に注目する.

$$
\begin{aligned}
& \frac{\cosh (c x)}{\cosh (c a / 2)}=\frac{\tanh (c a / 2)}{c a / 2} \\
& \times\left[1+\sum_{n=1}^{\infty}(-1)^{n} \frac{2 c^{2}}{c^{2}+p_{a n}^{2}} \cos \left(p_{a n} x\right)\right], \quad|x| \leq \frac{a}{2} \\
& \frac{\cosh (c y)}{\cosh (c b / 2)}=1 \\
& \quad-\frac{4}{\pi} \sum_{m=0}^{\infty} \frac{(-1)^{m}}{2 m+1} \frac{c^{2}}{c^{2}+q_{b m}^{2}} \cos \left(q_{b m} y\right), \quad|y| \leq \frac{b}{2}
\end{aligned}
$$

式(48)で $x=a / 2, c=\alpha$ とおくと次の関係を得る.

$$
\sum_{n=1}^{\infty} \frac{2 \alpha^{2}}{\alpha^{2}+p_{a n}{ }^{2}}=\frac{\alpha a / 2}{\tanh (\alpha a / 2)}-1
$$

また, 式(49)を $y=0 \sim b / 2$ で積分して, $c=\alpha$ とす ると次式の関係が得られる.

$$
\frac{8}{\pi^{2}} \sum_{m=0}^{\infty} \frac{1}{(2 m+1)^{2}} \frac{\alpha^{2}}{\alpha^{2}+q_{b m}^{2}}=1-\frac{\tanh (\alpha b / 2)}{\alpha b / 2}
$$

ついでに, 式(50) と対比して, 上式から次式を得る.

$$
\begin{gathered}
\sum_{m=0}^{\infty} \frac{2 \alpha^{2}}{\alpha^{2}+q_{b m}{ }^{2}}=\frac{\alpha b}{2} \tanh \left(\frac{\alpha b}{2}\right) \\
\text { 式(50)で } \alpha^{2} \rightarrow \gamma_{b m}{ }^{2}, \text { ここで, } \\
\gamma_{b m}{ }^{2}=\alpha^{2}+q_{b m}{ }^{2}
\end{gathered}
$$

と置き換え，さらに式(51)の関係を用いると，式(44) は次のように書き換えられる。

$$
\begin{aligned}
& S_{a b}\left(\xi_{n m}\right)=\frac{8}{\pi^{2}} \sum_{m=0}^{\infty} \frac{1}{(2 m+1)^{2}} \frac{\alpha^{2}}{\gamma_{b m}{ }^{2}} \sum_{n=1}^{\infty} \frac{2 \gamma_{b m}{ }^{2}}{\xi_{n m}{ }^{2}} \\
&=\frac{\alpha a}{2} \frac{8}{\pi^{2}} \sum_{m=0}^{\infty} \frac{1}{(2 m+1)^{2}} \frac{\alpha}{\gamma_{b m} \tanh \left(\gamma_{b m} a / 2\right)} \\
&+\frac{\tanh (\alpha b / 2)}{\alpha b / 2}-1
\end{aligned}
$$

同様にして,

$$
\begin{aligned}
S_{a b}\left(\eta_{n m}\right)= & \frac{\alpha b}{2} \frac{8}{\pi^{2}} \sum_{m=0}^{\infty} \frac{1}{(2 m+1)^{2}} \frac{\alpha}{\gamma_{a m} \tanh \left(\gamma_{a m} b / 2\right)} \\
& +\frac{\tanh (\alpha a / 2)}{\alpha a / 2}-1
\end{aligned}
$$

式(53) と (54)で, それぞれ第一項の級数は $\alpha$ ととも に大きくなる項である．また，第二項と第三項は $\alpha \rightarrow 0$ と $\alpha \rightarrow \infty$ での補正項であると見なすことがで きる. $\alpha \rightarrow 0$ では式(53) と（54）はゼ口に近づき，式 (45) の項もゼロであるので, 式(41) から $r_{m}(0)=1$ とな り，静的な関係に一致する.

また, $a \rightarrow \infty$ とすると, $r_{m}(s)$ は次の一次元鉄心の 結果 ${ }^{(4)}$ に一致することを確認できる.

$$
\begin{aligned}
& r_{m 1 b}(s)=\frac{\alpha b / 2}{\tanh (\alpha b / 2)}-\sum_{n=1}^{\infty} \frac{2 \alpha^{2}}{\beta_{b n}{ }^{2}} \frac{\tanh \left(\beta_{b n} l / 2\right)}{\beta_{b n} l / 2} \\
& \text { ここで, } \\
& \quad \beta_{b n}{ }^{2}=\alpha^{2}+p_{b n}{ }^{2}
\end{aligned}
$$

$5 \cdot 3$ 鉄心長さの影響の計算例 鉄心の長さを無 視した磁気抵抗

$$
\begin{aligned}
& r_{m a b}(s)=1 \\
& +\left(\frac{b}{a+b}\right)^{2} S_{a b}\left(\xi_{n m}\right)+\left(\frac{a}{a+b}\right)^{2} S_{a b}\left(\eta_{n m}\right)
\end{aligned}
$$

に対する相対磁気抵抗，式(41)の比

$$
\bar{r}_{m}(\omega)=\frac{r_{m}(j \omega)}{r_{m a b}(j \omega)}
$$

を計算して，長さの影響を調べる，計算には次のデー タを用いた(以下同様).

$$
\begin{aligned}
& \mu=5000 \times 4 \pi \times 10^{-7} \mathrm{H} / \mathrm{m}, \sigma=1.0 \times 10^{7} 1 / \Omega \mathrm{m}, \\
& b=10 \mathrm{~mm}
\end{aligned}
$$

計算結果の表示には $\omega(\mathrm{rad} / \mathrm{s})$ の代わりに周波数 $(\mathrm{Hz})$ を用い $(\omega=2 \pi f)$, 下式で定義される正規化周波 数 $\bar{f}$ を用いる.

$$
\begin{aligned}
& \omega_{b 1}=\frac{1}{\mu \sigma\left(\frac{b}{2}\right)^{2}} \\
& \omega_{b}=\left(1+\frac{b}{a}\right) \omega_{b 1} \\
& \bar{f}=\frac{f}{f_{b}}, \quad f_{b}=\frac{\omega_{b}}{2 \pi}
\end{aligned}
$$

ここで, $\omega_{b 1}$ は厚さ $b$ の一次元鉄心の場合に，極低周 波数域と高周波数域で適用できる簡単な式で近似した ときの折れ点角周波数を表す ${ }^{(1)}$.これはまた, 表皮の深 さの定義 ${ }^{(6)}$ から，厚さ $b / 2$ を表皮の梁さとする周波数 の $1 / 2$ に相当する. 一方， $\omega_{b}$ は同様な近似を二次元 鉄心に行ったときの折れ点角周波数ではなく, 後の計 算結果をある程度統一的に示すことができる，経験的 な基準の周波数である. 上のデータでは $f_{b 1}=0.101 \mathrm{~Hz}$, $a / b=2$ のとき, $f_{b}=0.152 \mathrm{~Hz}$ である.

$a / b=2$ のとき, 長さ比 $l / b$ をパラメタにして, 式 (58)の絶対値と偏角を図 2 に示寸. 鉄心長さの影響は 長さ比が大きいほど小さいが, 周波数が $\bar{f}=5$ 付近で 最も大きなっている. 長さ比を固定すると, 正方形鉄 心の場合が最も小さく，扁平な鉄心になるほど大きく なる. 図には $l / b=1$ のときに, 最も大きくなる一次元 
鉄心 $(a / b=\infty)$ の結果をも示している(このときの周 波数表示の基準は $\left.f_{b 1}\right)$.
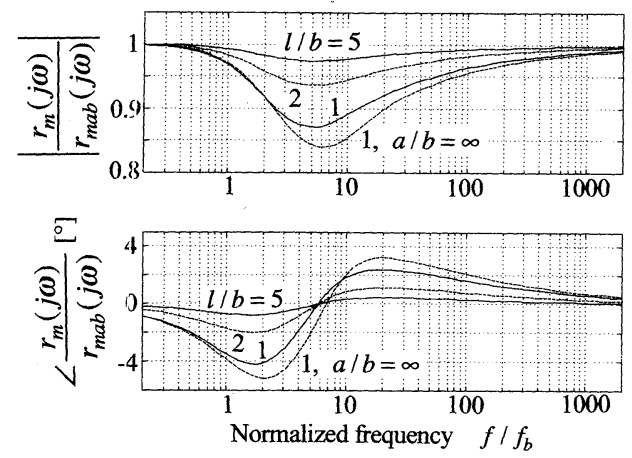

Fig. 2 Effect of core length on magnetic reluctance: eq. (58) for $a / b=2$.
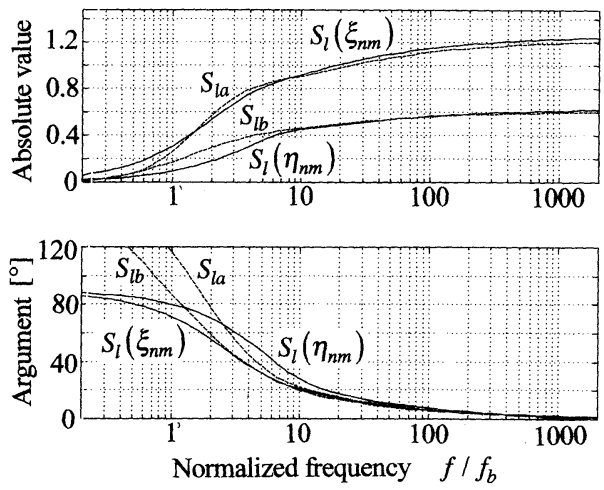

Fig. 3 Approximation of magnetic reluctance with core length: eqs. (45) and (62) for $a / b=2$ and $l b=1$.
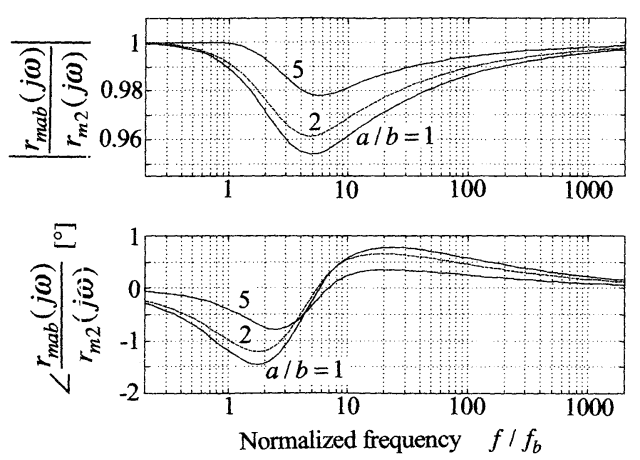

Fig. 4 Comparison of magnetic reluctance without iron-core length between two-and three- dimensional models: eqs. (57) and (63).

\section{6. 近似部算式}

6.1 鉄心長さの項の計算式 式(45)の計算は高周 波数域では収束が遅く，かなり多くの項数を計算する 必要がある.ここでは次の近似式を提案する.

$$
\begin{aligned}
S_{l a}= & {\left[\frac{\tanh (\alpha a / 2)}{\alpha a / 2}-1\right] } \\
& \times \sum_{m=0}^{\infty} \frac{1}{(2 m+1)^{2}} \frac{\alpha^{2}}{\gamma_{b m}{ }^{2}} \frac{\tanh \left(\gamma_{b m} l / 2\right)}{\gamma_{b m} l / 2}
\end{aligned}
$$

ここで, $S_{l}\left(\xi_{n m}\right)$ の近似式であることを明示するため に, 下添え字 $a$ を付けた. $S_{l}\left(\eta_{n m}\right)$ については上式で $a$ と $b$ を㯰き換える.

上の近似式を式(45) と比較した計算例を $a / b=2$, $l / b=1$ の場合に図 3 に示す. 式(62)の近似は高周波 数域ではわずかに小さな絶対值をとり，中周波数域で は大きくなっている. 式(45)の絶対値は単調増加で, 高周波数域ではおよそ $0.63(a / l)$ の実数值に漸近する.

6.2 二次元モデルとの比較 断面方向の磁界分布 を無視し，長さ方向の磁界を $x$ と $y$ の二次元分布とし て得られた磁気抵抗は次のように表される ${ }^{(1)}$.

$$
\begin{aligned}
& \frac{1}{r_{m 2}(s)}=\frac{\tanh (\alpha b / 2)}{\alpha b / 2} \\
& +\frac{8}{\pi^{2}} \sum_{m=0}^{\infty} \frac{1}{(2 m+1)^{2}} \frac{\alpha^{2}}{\gamma_{b m}{ }^{2}} \frac{\tanh \left(\gamma_{b m} a / 2\right)}{\gamma_{b m} a / 2}
\end{aligned}
$$

上式は式(57)の形よりもかなり簡単な式であるが，鉄 心長の影響を除いた項としては式(63)の方が正確であ ると考えられる.これらの式は極低周波数域と高周波 数域では一致することが確認できるが，中間周波数域 では一致しない.式(63) と比較することによって式 (57)の近似度が推測でさると考えられる.

両者の磁気抵抗の比 $r_{m a b}(j \omega) / r_{m 2}(j \omega)$ を絶対値と 偏角とで図 4 に示す，絶対值は式(57)の方がわずかに 小さく，差違は正規化周波数 5 付近で最も大きい，ま た, 正方形断面 $(a=b)$ の場合が最も大きく，絶対值 で最大 $5 \%$ 弱である $(a / b=2$ の場合との差違は小さ いので計算例にはこちらを用いている)。偏角は 1.5 度以内で非常に小さい. したがって，条件式(10)を考 虑しなかったことによる誤差は $5 \%$ 以下で小さいと推 測される.差違が扁平な鉄心になるほど小さいことは, 無限幅の場合に一次元鉄心の場合に一致するという先 の確認から理解できる.

また，計算上では，式(53) と式(54)の級数よりも式 (63) の級数の方が収束性がはるかに良い. 以上のこと から, 式(57)よりも式(63)の方が妥当であると考える.

6.3 計算式 以上の結果を踏まえて, 磁気抵抗の 計算式を次式のように書くことにする.

$$
r_{\text {map }}(s)=r_{m 2}(s)-r_{\text {mlap }}(s) \text {, }
$$




$$
r_{\text {mlap }}(s)=\left(\frac{b}{a+b}\right)^{2} S_{l a}+\left(\frac{a}{a+b}\right)^{2} S_{l b}
$$

このとき, $S_{l a}$ と $S_{l b}$ の級数計算の収束性は $r_{m 2}(s)$ の級 数のそれと同程度である. また, 高周波数域では式(41), (53)，(54)，(62) から, 次のように近似する.

$$
r_{m \infty}(s)=\frac{a}{a+b} \frac{\alpha b}{2}=\sqrt{\frac{1}{1+b / a} \frac{s}{\omega_{b}}}
$$

この表現は，厚さ $a$ と $b$ 二つの一次元鉄心の，高周 波数域での並列結合である.

式(41) と式(64)との比較, 鉄心長を無視した式(63) と(65)の近似度を, 上と同じデータに対して図 5 に示 寸. 式(64)の計算值(破線で示す)は式(41)のそれに非 常に近い值を示している. また，式(63) と式(64)の差 は鉄心長さの影響で, $1<\bar{f}<50$ で目立つがそれほど 大きくはない.この差は鉄心長さが相対的に大きくな るにつれてさらに小さくなる. 普通の鉄心では $l / b$ が もっと大きいので, 鉄心長さの影響はさらに小さくな
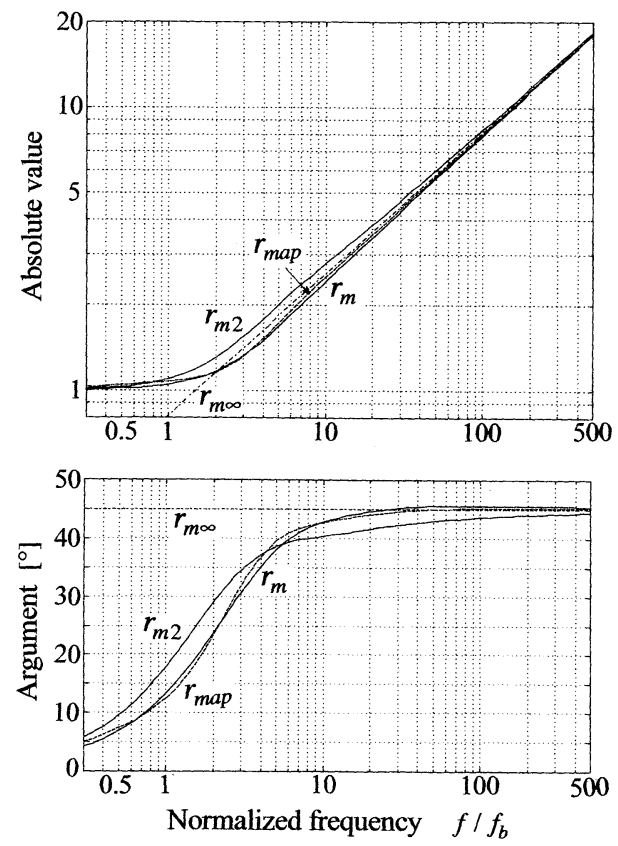

Fig. 5 Approximation of magnetic reluctance: eqs. (41), (63), (64) and (65) for $a / b=2$ and $l b=1$.
る. 偏角をも考慮に入れると，鉄心長を無視した高周 波数域での近似式(65)も $\bar{f}>5$ で良い近似を与えてい る.

\section{7. 結 び}

空隙部に挟まれた矩形ソリッド鉄心の磁気抵抗につ いて, 簡単な二次元解析モデルの有用性を検討するた めに, 鉄心の端面付近の磁界分布を考慮して磁気抵抗 の解析モデルを求めることを試みた. このとき, 磁界 分布を求める際に，一般化された関数を利用して，無 限級数の和を論じた. また, 磁界分布モデルが鉄心の 側面で一部に不自然さを含むことから，得られたモデ ルは近似解である.ただし, 端面の効果を無視した部 分が正確とみられる二次元モデルと比較して, 差違が 小さいことから，よい近似であるといえる，モデルの 計算式が収束性に問題を含み複雑であるために，二重 の級数和を一重に減らした近似計算式を提案した。

計算モデルを用いて，鉄心長さの影響を計算例で調 べた. その結果, 普通に用いられる鉄心では鉄心長の 影響は小さいことを確認した.

\section{文献}

(1) Feeley, J. J., A Simple Dynamic Model for EddyCurrents In a Magnetic Actuator, IEEE Trans. on Magnetics, Vol.32, No.2, pp.453-458, 1996.

(2) Fukata, S., A Frequency-Domain Model of Electromagnetic Actuators Composed of Solid Iron Cores, JSME Int. Journal, Vol. C-43, No. 1 (2000), pp.38-46.

(3) Fukata, S., Frequency Characteristics of Electromagnets Composed of Solid Iron Core, Proc. of the 12th Symposium on Electromagnetics and Dynamics (in Japanese) (2000), pp. 153-156.

(4) Fukata, S., An Analysis of Frequency Characteristics of Magnetic Actuators, Trans. of JSME, Series C, Vol. 71, No. 709 (2005), pp. 2746-2753.

(5) Stoll, R.L., The Analysis of eddy currents, Clarendoon Press, pp. 4-6, Oxford, 1974.

(6) Umoto, S., Electromagnetics, Shoukoudo (1993), pp.17-18, p. 326.

(7) Hsu, H.P., Fourier Analysis (in Japanese, translated by Satou, H.), Morikita-shuppan (1991), pp. 46-55, pp. 37-38, pp. 10-12, p.62

(8) Schwart, L., Methods of Mathematics for Science Physicst (in Japanese Translated by Yoshida, K. and Watanabe, J.), Iwanami-Shoten (1973), pp.155-157. 